in all possible directions from the epicentre combined in a single plane. If the velocity is different in different directions, in the general figure these differences will be eliminated when the number of observations is large enough, and the result will be a curve free from local disturbances.

Although the time has not yet come for us to determine the definite form of an earthquake-hodograph, yet we know enough from the best examined earthquakes to decide whether the hodograph is an hyperbola or a curve with points of inflexion, whether Hopkins' law is confirmed by the observations, or an increase of velocity is noticeable in the outer zone of the disturbed area.

The best example for such an investigation is contained in von Seebach and Minnigerode's discussion of the earthquake of March 6, 1872, in Central Germany. An inspection of the map of coseismals published by them is sufficient to show that the horizontal coseismals are crowded together in a striking manner near Göttingen and Leipzig, at a distance of sixteen (German) miles from the epicentre. Accordingly, in drawing the hodograph we see how badly the hyperbola suits the observations. Several points which are most valuable for the determination of the epicentre, because they are nearest to it, and which agree most perfectly with one another, must be rejected in constructing the hyperbolic hodograph, in order that the earthquake may not begin at the surface of the earth until I $\frac{1}{2}$ minutes after it was actually observed at five different places at five to six miles distance from the epicentre. For sixteen miles the hyperbola leaves all the best observations below it, after which nearly all points remain above it until it ends at Breslau, at a distance of fifty-seven miles from the epicentre. At this place a magnetic needle was found swinging by Prof. Galle a 4h. 5m. 25s., Berlin time, but the shock itself may have occurred several minutes earlier. The hyperbola is made to pass exactly through the point corresponding to this time, for otherwise its vertex would have to be placed still higher than it is now, and this would increase the already existing disagreement between the calculated time of the beginning of the earthquake and the actual observations.

How well, on the contrary, are the observations represented by a curve the vertex of which is a little below $3 \mathrm{~h} .55 \mathrm{~m}$., and, being convex downwards, passes at a distance of seven to eight miles between $3 \mathrm{~h} .55 \mathrm{~m}$. and $3 \mathrm{~h}$. $56 \mathrm{~m}$., reaches its points of inflexion at about eleven miles distance with a slope corresponding to 2.5 miles per minute, and then leaving some points on one side and some on the other, passes through Tiibingen $(36 \%$ miles), the last trustworthy point, until it reaches Breslau one minute before the observed time, with a velocity of at least fifteen miles a minute.

The Herzogenrath earthquake of October 22, 1873 , leads to somewhat similar results. In drawing the hyperbolic hodograph, some of the best observations, those used for determining the position of the epicentre, have to be rejected altogether, while others must be supposed to err by as much as two or three minutes. But a curved line, passing through the mean positions of the points, is concave throughout on its lower side, with a large curvature at the epicentre. The figure certainly differs little from the form of the hodograph corresponding to a centre at the surface, and the inner zone is a circle of not more than four kilometres radius.

Thus the best investigated earthquakes at our disposal show that the observations agree much less closely with the older theory of concentric earthquake-waves, straight rays and hyperbolic hodograph, than they do with the new theory of a velocity of propagation increasing with the depth, rays convex downwards, and a hodograph with points of inflexion.

The Determination of the Depth of the Centre.-If the law connecting the velocity with the depth were known, we should be able to calculate the forms of the corresponding rays and hodograph, and to find a relation between the depth of the centre and the form of the hodograph. In Fig. 2 we have started with the simplest assumption, and supposed the velocity to vary as the depth. As this law is an entirely arbitrary one, the figure can only give a nearer approach to the truth than the theory represented in Fig. I. If, for instance, the modulus of elasticity were to vary as the depth, the velocity would change much more rapidly near the earth's surface than far below it ; and the fact that the perceptibility of earthquakes decreases so rapidly as the depth increases, certainly indicates that a rapid change in the velocity takes place immediately below the surface. Consequently, in calculating the depth of the centre correspond- ing to our law, we should find too large a value. Other difficulties in determining the depth of the centre are our ignorance of the true superficial velocity, and the uncertainty as to the form of the hodograph, especially the doubtful position of its points of inflexion. But, in spite of all these difficulties, we may consider it as a rule that the depth will increase with the radius of the inner zone of the disturbed area, and that it will certainly always be smaller than this radius.

On the other hand, a minimum value of the depth may be found by means of the tangent at the point of inflexion. This tangent in Fig. 2, like the asymptote in Fig. I, makes an angle of $45^{\circ}$ with the horizon, because in both figures the central velocity $\left(u_{1}\right)$ was taken as the time scale. While in Fig. I the asymptote passes through the centre, in Fig. 2 the tangent at the point of inflexion passes above it. Now, let us imagine the depth of the centre in Fig. 2 to remain the same, as well as the velocities $\iota_{1}$ at the centre, and $u$ at the surface; but let the increase of velocity be no longer uniform as before, but be principally restricted to the neighbourhood of the surface. The consequence will be that the rays will differ little from straight lines at first when they leave the centre, and that the principal increase of curvature will be near the surface. The point of emergence of that ray which leaves the centre horizontally, will move to a greater and greater distance, and, as the same is the case with the point of inflexion of the hodograph, its tangent at that point will be displaced parallel to itself downwards; and when the whole change is imagined to take place in the surface itself, the hodograph will coincide with Seebach's hyperbola, and the tangent at the point of inflexion becomes an asymptote and passes through the centre.

Thus, with a hodograph adapted as well as possible to the existing observations, we find a depth of more than five, and less than ten, geographical miles for the earthquake in Central Germany, and a depth of less than three kilometres for the earthquake of Herzogenrath. Each of these earthquakes represents a special type. Type I., with a very small depth of centre and an approximate disappearance of the inner zone, is represented by the earthquake of Herzogenrath; Type II., in which both zones are pretty equally distinct, and the depth is rather considerable, by the earthquake of Central Germany. There may exist a Type III. with a very deep centre, or with small intensity and moderate depth, for which the point of inflexion of the hodograph falls outside the region when the earthquake is perceptible, and where, consequently, the hodograph is convex throughout. Amongst the earthquakes so far studied, for which the mean velocity has been calculated, those with small velocities, which generally have a merely local character, may safely be regarded as belonging to the first type.

\section{THE TOTAL SOLAR ECLIPSE OF AUGUST 8,} I $896 .^{1}$

I T having come to my knowledge that some doubts had arisen as to the suitability of Norway as a post of observation for the total eclipse of the sun in 1896, and having had both experience in total eclipse expeditions and of travelling in Norway, I determined to make a special tour of observation both to the west coast, and also to Finmarken, Lapland, and the Russian frontier on the east coast.

In selecting stations in such an exceptional country as Norway, many points must be considered that do not apply to most places; thus it is not enough to know that $\mathrm{A}$ is twenty miles from $B$ without also knowing how many fjords lie between, how many peaks three or four thousand feet in height, how many glaciers, and how far they are crevassed, if the mountains are passable, and if so what weight besides himself a man can carry up. Those people who have visited Norway, and the more so those who have travelled in the interior and north of the country, are surprised at the almost impossibility of moving at all except by the fjords and certain made roads. These generally may be said to extend as far north as Trondhjem, latitude $63^{\circ} 26^{\prime}$; longitude $10^{\circ} 30^{\prime}$ about. After that, on the north and north-east coast and Russian frontier, roads are the feeblest tracks generally, and the fjord communication only of a special character ; the population, except at such places as Tromso, Hammerfest, Vardo, and Vadso, is very scanty, and chiefly confined to the sea coast, and in the latter case subject to consider-

1 Abridged from a paper read before the Koyal Astronomical Society, by Col. A. Burton-Brown (Monthly Notices, R.A.S., vol. lv. No. 3).

NO. I $35^{6}$, VOL. 52$]$ 
able variation, according to the season of the year and the nature of the fishing. How far these points would affect an astronomical expedition will be seen later on.

From Trondhjem we take a north-north-east course, passing Torghatten, an island of about 800 feet in height, and shortly after pass the island of Donnæso, at the bottom of the map on the west side, which will be on the border of the shadow during totality; steaming north to Tommen Öe, which will have about one minute totality, a careful search for stations is kept. Lüröe is too low, Oxtinden promontory too much inland. Hestmandöe, well within the $85^{\prime \prime}$ line, and the island of Tränen, near the I th parallel, are too far west, though the central line passes close by ; but having a longitude of only $12^{\circ} 5^{\prime}$, the sun is rather low. The height of ground is 3710 feet. Röd Löven also, somewhat further eastward, and Bolgen, a peaked island, close to the central line, are rather too far westward; passing Omnæs Oe and Melöe, crossing the central line, we next miles direct north of the central line, where there is a hill to the north-east of the town. Excellent accommodation can be had there, and a telegraph station exists. Further north is the island of Lande Gode, within the $85^{\prime \prime}$ limit. The islands of Lundo and Engelo are on the northerly limit of the shadow of totality, and therefore useless. If Bödo were occupied as headquarters, with a steam launch at the disposal of the party, and Sandhornet, Arnöe, Fleina, Kunnen, or the lighthouse rock of Slöt, Bolgen, Röd Löven, or Hestmando as detached stations, a valuable area would be covered, although these positions have the astronomical disadvantage of the sun's altitude being as low as $6 \frac{5}{6}^{\circ}$ to $7 \frac{3}{4}^{\circ}$, and the duration of totality but little over $1 \frac{1}{4}$ to $I \frac{1}{2}$ minutes. Yet, owing to the stillness of the atmosphere on the west coast of Norway at that time, and the general freedom from clouds on the horizon, some good results should be obtained. The further fact of the corona being seen through a considerable thickness of watery vapour would have both a spectroscopic and photographic

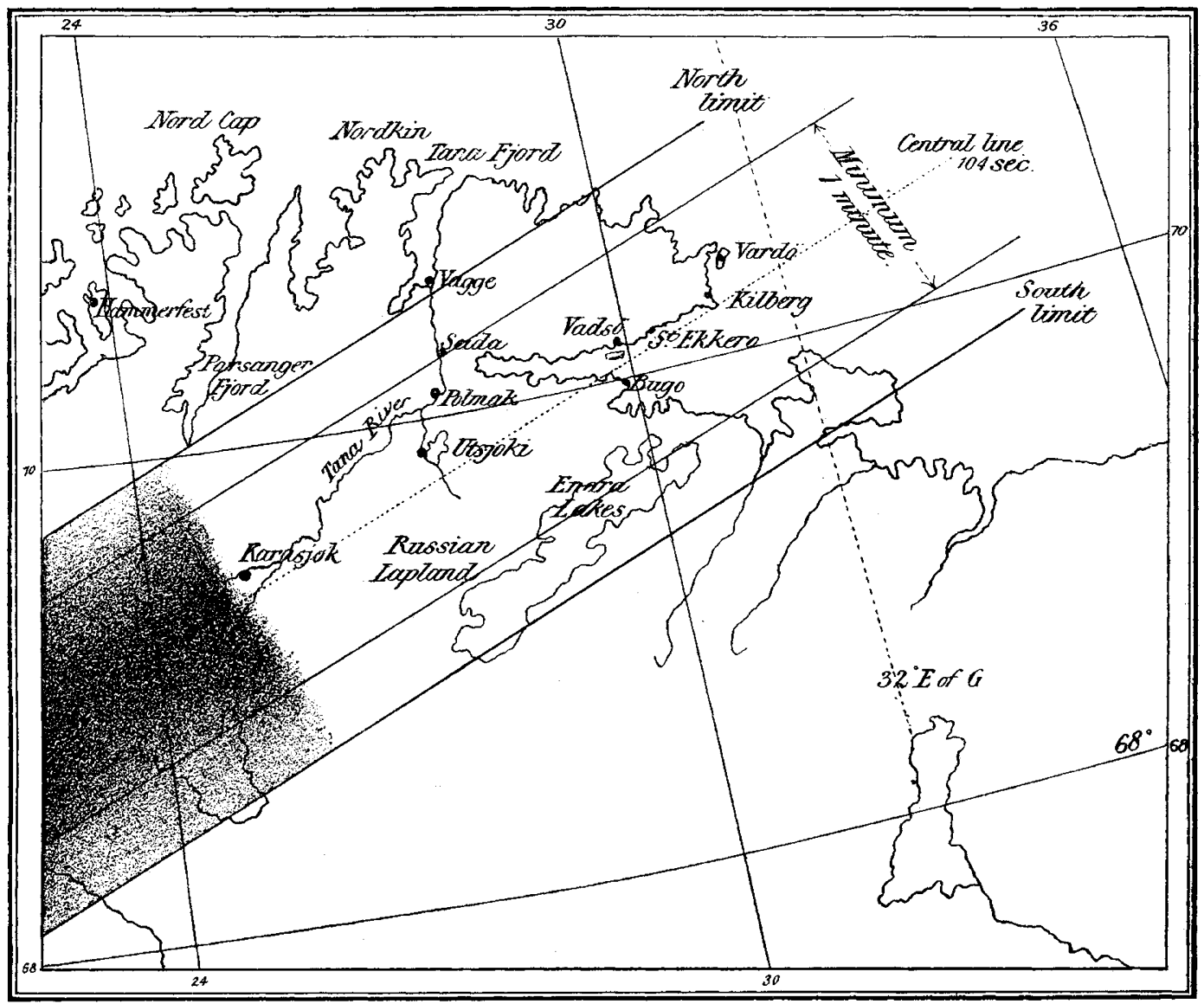

round the promontory of Kunnen, two or three miles above the central line, a rather inaccessible position of some 2000 feet high. The lighthouse island of Slot is, however, in all respects a desirable position, and Kunnen has a telegraph station-a valuable adjunct. Proceeding east-north-east the Island of Fugloe is pasced, 2300 feet high, steep and rugged; and $1 \frac{1}{2}$ miles further north, Fleina, about 100 to 1000 feet-a good position. On the right is the island of Sandhorn, with the Sandhornet Mountain of 3300 feet-a rare position for mountaineers, only about five or six miles above the central line, with a minute and a half totality, and the sun an altitude of $7 \frac{1}{2}$ about, the longitude being six or seven minutes over $14^{\circ}$. This position gives an uninterrupted view all round. For non-climbers the Arnöe Islands on the west, where there are fishing stations, would afford an almost equally good position. These places are in easy communication with Bödo, the latitude of which is $67^{\prime} 17^{\prime}$, and longitude $14^{\circ} 24^{\prime}$ about, and which is ten NO. I 356 , VOL. 52$]$ interest in comparison with similar observations taken at about double the altitude on the east coast. Although several islands could be used as sites for stations, experience has shown some to be better adapted for many reasons than others. Thus Fuglöe is steep and rusged, and has no advantages over Fleina except height ; also Omnæs (le is a troublesome place; Kunnen is an almost inaccessible promontory of chert and granite rocks; the island of Slöt has a good anchorage for boats, and the sun would not be masked by Kunnen during totality. Here also is a telegraph station.

Leaving the west-coast positions, we reach Tromso, and steaming up to Hammertest, signs of civilisation die fitjully away. After rounding the North Cape, $71^{\circ} 1^{\prime} 40^{\prime \prime} \mathrm{N}$, and about $26^{\circ}$ E. and steering east, the Nordkin is passed, and from there in a south-east direction we travel along a bleak, inhospitable shore of quartzite rocks to Vardo, on an island; this is about the northeast corner of Norway, a good-sized whaling station, and a fort, 
with some second-class hotel accommodation. This place was used as an observing station in 1769 by the Austrian Hell for the transit of Venus; and, being less than twelve miles directly north of the central line of shadow, might be advantageously occupied. It forms the most easterly station ; being in longitude $31^{\circ} 8^{\prime}$, and latitude about $70^{\circ} 22^{\prime}$, it would have a duration of totality of over Im. 3 Is., and the sun's altitude will be about $14 \frac{1}{2}^{\circ}$ It is easily accessible, no high ground obstructs the view, and provisions and labour are to be had. Passing south down a dreary coast of quartzite rocks and Silurian slates, we come to Kilberg, about ten miles south, and two miles inland. There is a hill about 500 feet high, but although this would be only five or six miles north of the central line, it is not in other respects a desirable station. Steaming south-south-west we pass Stcre Ekkero, a promontory some twenty-five or thirty miles west of Vadso, which appears to have all the attributes of a good station, provided accommodation can be arranged for: the central line of totality passes over the southern point, and there is a free view to the south-south-east and east-north-east, the sun's azjmuth at the local time of $18 \mathrm{~h}$. being $97^{\circ}$ south towards east, and the duration of totality a maximum-viz. over $\mathrm{Im}$. $4 \mathrm{rs}$, the sun's altitude about $14^{1^{\circ}}$. Passing on to Vadsö, the town of the Finmarken district, there are several hills, two or three hundred feet, easily accessible, and in all respects suitable for observing stations within three or four miles ; indeed, Vadsö should be looked upon as the headquarters of an East Norway expedition. The local time of totality here would be $17 \mathrm{~h} .57 \mathrm{~m}$. $46 \mathrm{~s}$., and duration about $1 \mathrm{~m}$. $35 \mathrm{~s}$. All the aforementioned places are in telegraphic communication with most parts of Norway during the fishing season, and no doubt arrangements could be made for keeping the offices open as late as August 8 . The temperature at Vadso is remarkably high, probably between $50^{\circ}$ and 60 F. in August, and there is every chance of fine weather at that time.

Crossing the Varanger Fjord we come to Bugö, a Lapp fishing station, and within a mile and a half of the central line; the longitude is about $29^{\circ} 50^{\prime}$, and latitude $69^{\circ} 58^{\prime}$. There the duration would be about $\mathrm{Im}$. 40s, with nothing to obstruct the view ; frequent communication could be had with Varlsö at certain times of the day; heliograph signals might be transmitted ; there are several sites hereabouts, but one in particular desirable. The Bugönæsfjeld I will leave to those who like to be in the clouds! So little is known of it that every map shows it in a different position; but if intrepid mountaineers are fond of carrying half-hundred-weights up mountains, there is no reason why they shculd not have the satisfaction they desire, but they will find no one to do it for them.

In order to distribute the parties and multiply the chances of success, one party might proceed from Vadsö to Seida, on the Tana River, This station is a good one for all points except the length of totality, which is only about Im. I2S., and has the sun at an altitude of about $13 \frac{1}{2}^{\circ}$. Polmãk, some twelve miles due south (reached by poling up the river), is not so easily got at, but astronomically better situated, and south-east of it, about five miles, is a mountain over Icoo feet high. About forty or fifty miles further up this river, in a south-west direction, is Utsjoki, a place also that might be advantageously occupied in the Russian Lapland. The duration of totality there would be about $\mathrm{Im}$. 26s., and the sun's altitude about $13^{\circ}$; both at Polmãk and Utsjoki camp equipage would have to be taken. Both are in telegraphic communication with Vadso and Vagge, the latter place being at the mouth of the Tana Fjord. Karasjok is astronomically a geod place, within four miles of central line, the sun's altitude being about $12 \frac{1}{4}^{\circ}$ and duration of totality over $\mathrm{I} \frac{1}{2} \mathrm{~m}$. Much, of course, will depend on the number of observer it is proposed to send out, their powers of endurance, and knowledge of Lappish, Russian, and Norwegian for the east coast expeditions (except at Vardo).

To the information which Colonel Burton-Brown has brought together, we may add that the Orient Steam Navigation Company propose to send one of their large steamships to Vadsö, for the purpose of enabling observations to be made of the eclipse. The steamer will leave London on July $2 \mathrm{I}$, and, after calling at Odde, Bergen, Naes, Molde, Trondhjem, Hammerfest, and North Cape, will arrive at Vadsö on August 3. It will leave a week later, and will arrive in London on August I 7. (Full particulars of this journey will be found in our advertisement columns.)

We are informed by Messrs. Cook a nd Son that the Bergenske
Steamship Company have consented, subject to certain conditions, to send one of their best steamers from Bergen and Trondhjem to Vardo and back, for the purpose of enabling persons interested in astronomy to view the eclipse. It is proposed that the steamer shall leave Bergen on July $3 \mathrm{I}$, calling at Trondhjem two days later, reaching Vardo on August 8, and remaining until 4 p.m. on August 9, returning to Trondhjem August I 3, and Bergen August I 5. The steamer will call at all the usual places visited by the tourist steamers between Bergen and the North Cape.

\section{UNIVERSITY AND EDUCATIONAL INTELLIGENCE.}

CAMBRIDGE.-Mr. Herman, of Trinity College, is appointed Chairman of the Examiners for the Nathematical Tripos.

The University Lecturer in Cieography (Mr. H. Yule Oldham) announces a course of lectures on the Elements of I'hysical Geography during the present term. The Royal Geographical Society's Studentship of $\oint_{1} \mathrm{IOO}$ will be awarded at Easter. Candidates must be members of the University who have attended the courses of the University Lectures.

The Council of the Senate recommend that the University of Allahabad be adopted as an affiliated University on terms corresponding to those in force for the University of Calcutta.

The report of the Syndicate on the Higher Local Examina. tions shows that good results have been attained in the scientific subjects. The new laboratory examination appears to work well, and has had a wholesome effect on the candidates' training.

Mr. W. C. D. Whetham and Mr. J. W. Capstick have been recognised as Teachers of Physics, and Mr. R. H. Adie as a Teacher of Chemistry, for medical degrees.

Among the freshmen who have matriculated this term, there are over $I 50$ students of medicine.

Slowly, but surely, the system of paying teachers of elementary science according to the examinational successes earned by their students-in other words, according to their ability to cram young students with a large assortment of scientific facts, dogmatically stated and imperfectly understood-is giving way to one more calculated to create and foster a desire for natural knowledge. Within the past few days a Minute has been issued to schools under the Department of Science and Art, stating that the Lords of the Committee of Council on Education have decided to try the experiment of making grants for instruction in science and art depend partly upon the attendance of the student and partly on payments on results as tested by examination. The Committees of Science and Art Schools and Classe which have been in the recejpt of grants from the Department for two consecutive years, or which are conducted by a local authority under the Technical Instruction Act I889, or the Technical Schools (Scotland) Act 1887 , will be allowed to elect to receive their grants on the scheme under which the payment on results will be one-half those on the present scale, while attendance grants will take the place of the other half, provided that the Inspector of the Department reports that the teaching and equipment of the school are thoroughly satisfactory, and that the class or classes are not too large for instruction by the staff of teachers. The attendance grant will be $\mathrm{I} d$. for each attendance of at least an hour's duration in a day science class, and $2 d$. in a nigh science class, and of $3^{d}$. for each attendance of cne and a half hours' duration given to practical work in chemistry, physics, metallurgy, or biology, in a properly equipped laboratory. Applications to receive grants under the new Minute must be received before December I, I 896 , and in subsequent years before November I. But the sanction to be so treated may be withdrawn at any time should it appear from the results of the examination in May, or from the reports of the Inspectors, that the instruction is not efficient ; and no school can receive grants partly under the new Minute and partly under the ordinary scale of payments on results. Organised science schools are exempter from these attendance grants; nor can the grants be claimed on behalf of students who are on the register of an elementary school. The principle of recognising attendance at classes as one of the tests of the efficiency of a school has common sense at the back of it, and it should do something to reduce the baneful influence of the examination fiend upon elementary scientific education.

$$
\text { NO. I } 356 \text {, voL. } 52]
$$

